\title{
Edukasi Streching Cervical pada Kasus Neck Pain di SMA 5 Merangin
}

\author{
Wanti Hasmar ${ }^{1}$, Putra Hadi ${ }^{2}$ \\ ${ }^{1,2}$ Program Studi D III Fisioterapi, STIKes Baiturrahim Jambi \\ e-mail:wanti.cemar@gmail.com
}

Submitted : 22/07/2021

Accepted: 08/01/2022

Published: 28/01/2022

\begin{abstract}
The use of smartphones or communication tools that can be easily connected to the internet has increased from time to time. Neck Pain that occurs in students can affect various aspects of life, such as reduced work productivity, disrupted quality of life, and school activities. Community service activities were carried out in March-April 2021 with discussion methods and presenting materials and illustrated posters related to cervical stretching education in Neck Pain cases through Zoom Meetings. In this illustrated poster there are 4 cervical stretching movements. This Community Service (PKM) aims to be used as a source of knowledge and management of neck pain and neck stiffness due to neck pain in high school students 5 Merangin. The results of the evaluation through questions and answers through the Zoom Meeting application are that on average students know and can practice cervical stretching correctly, and complaints of neck pain and neck stiffness are reduced.
\end{abstract}

Keywords : cervical stretching, neck pain, zoom meeting

\begin{abstract}
Abstrak
Penggunaan smartphone atau alat komunikasi yang dapat dengan mudah terhubung dengan jaringan internet ini mengalami peningkatan dari waktu ke waktu. Neck Pain yang terjadi pada pelajar dapat mempengaruhi berbagai aspek kehidupan, seperti berkurangnya produktivitas kerja, terganggunya kualitas hidup, dan aktivitas sekolah. Kegiatan Pengabdian masyarakat dilaksanakan pada bulan Maret-April 2021 dengan metode diskusi dan menyampaikan materi serta poster bergambar terkait edukasi stretching cervical pada kasus Neck Pain melalui Zoom Meeting. Didalam Poster bergambar ini terdapat 4 gerakan stretching cervical. Pengabdian kepada Masyarakat (PKM) ini bertujuan untuk dapat dijadikan sebagai sumber pengetahuan dan penanganan nyeri leher dan kaku kuduk akibat Neck Pain di siswa SMA 5 Merangin. Hasil evaluasi melalui tanya jawab melalui aplikasi Zoom Meeting tersebut adalah rata-rata siswa mengetahui dan dapat mempraktekkan cara stretching cervical dengan benar, serta keluhan nyeri leher dan kaku kuduk berkurang.
\end{abstract}

Kata kunci : neck pain, streching cervical, zoom meeting

\section{PENDAHULUAN}

Setiap orang memiliki kewajiban untuk menjaga kondisi kesehatan yang sangat berkaitan dengan kualitas hidup. Kualitas hidup dapat terganggu oleh beberapa gejala, salah satunya adalah nyeri kepala. Menurut (Falavigna et al., 2013) bahwa nyeri kepala pada penduduk Brasil 93\% terjadi pada laki-laki dan 99\% pada perempuan dengan pravelensi penderita Neck Pain 69\% dialami laki-laki dan $88 \%$ pada perempuan. Neck pain yang terjadi pada pelajar atau mahasiswa dapat mempengaruhi berbagai aspek kehidupan, seperti berkurangnya produktivitas kerja, terganggunya kualitas hidup, dan terganggunya aktivitas sekolah.

Mahasiswa/siswa dapat mengidap nyeri kepala tipe tegang $(\mathrm{TH})$ karena memiliki beban akademik yang tinggi sehingga menyebabkan tekanan fisik dan mental (Suryawijaya, 2017), sedangkan aktivitas siswa yang menatap layar komputer dengan ergonomi yang tidak benar secara terus menerus pada saat mengerjakan tugas dapat menyebabkan nyeri otot, kaku dan pegal sekitar leher. Titik nyeri biasanya dirasakan pada otot 
upper trapezius,otot infra spinatus dan otot levator scapula, tetapi lebih sering menyerang otot upper trapezius.

Menurut (Bendtsen, 2009) peristiwa tersebut dapat menjadi salah satu faktor pencetus terjadinya $\mathrm{TH}$. Jenis sakit kepala inimerupakan sakit kepala bilateral dengan tanda seperti mengikat, menekan yang bersifat ringan sampai sedang (Buckley, Bull and Poulton, 2015) dengan faktor pemicu seperti stres, depresi, kegelisahan dan menggunakan smartphone dan laptop yang lama.

Edukasi stretching cervical merupakan solusi untuk mengurangi keluhan pada Neck Painpada siswa SMA 5 Merangin, untuk itu diperlukan sosialisasi berupa edukasi stretching cervical pada kasus neck pain. Tujuan pengabdian masyarakat ini adalah mengurangi keluhan nyeri leher, kaku kuduk saat menggunakan smartphone atau laptop untuk belajar online. Metode yang digunakan adalah via Zoom Meeting berupa penjelasan menggunakan media power point dan video mengenai kasus Neck Paindan cara stretching cervical. Kegiatan ini dilaksanakan secara online pada siswa SMA 5 Merangin.

Edukasi stretching cervical pada kasus Neck Paindi SMA 5 Merangin melalui online dengan aplikasi zoom meeting, kemudian siswa memberikan respond an diskusi hasil yang diharapkan pada pelaksanaan pngabdian masyarakat ini adalah agar siswa memahami dan dapat mempraktekkan stretching cervical untuk mengurangi keluhan nyeri dan kaku kuduk pada kasus neck pain. Kegiatan pengabdian masyarakat ini diawali dengan survei online untuk mengetahui bagaimana tingkat pengetahuan siswa SMA 5 Merangin selama sosialisasi pengabdian masyarakat dilakukan.

\section{TARGET DAN LUARAN}

Target luaran Pengabdian masyarakat ini adalah dengan melakukan sosialisasi dan edukasi stretching cervical pada kasus Neck Painyang dilakukan online dengan aplikasi zoom meeting pada siswa SMA 5 Merangin, dengan harapan dapat dijadikan sebagai sumber pengetahuan siswa SMA 5 Merangin, serta dapat mengurangi keluhan berupa nyeri leher dan kaku kuduk yang diakibatkan neck pain. Di dalam poster bergambar ini terdapat 4 gerakan stretching pada cervical.

Selain menghasilkan media leaflet dan poster pengabdian masyarakat ini memiliki luaran publikasi karya tulis ilmiah dan sebagai bahan ajar pada mata kuliah terapi latihan dan non musculoskletal.

\section{METODE PELAKSANAAN}

Kegiatan Pengabdian masyarakat dilaksanakan pada Bulan Januari-Februari 2021 dengan sasaran siswa SMA 5 Merangin. Kegiatan Pengabdian Kepada Masyarakat (PKM) ini bertujuan untuk meningkatkan pengetahuan dan dapat mempraktekkan atau menerapkan cara stretching cervical di SMA 5 Merangin dalam pelaksanaan edukasi stretching cervical pada kasus neck pain.

Kegiatan pengabdian masyarakat ini diharapkan dapat meningkatnya pengetahuan siswa di SMA 5 Merangin dalam edukasi stretching cervical dan dapat menerapkan latihan tersebut saat terjadi keluhan nyeri leher dan kaku kuduk.

\section{Pelaksanaan Kegiatan}

Tahap pelaksanaan kegiatan pengabdian kepada masyarakat ini adalah sebagai berikut :

1. Persiapan

Tahapan ini merupakan tahapan awal dari pelaksanan Pengabdian Masyarakat, sebelumnya tim pengabdian masyarakat melakukan survey dengan cara berdiskusi denga salah satu siswa SMA 5 Merangin, setelah itu mengirimkan surat berupa perizinan dari Kepala Sekolah SMA 5 Merangin pada 
bulan februari 2021. Setelah mendapat izin, selanjutnya Tim Pengabdian Masyarakat melaksanakan sedikit diskusi kembali dengan salah satu siswa SMA 5 Merangin terkait Pengabdian Masyarakat yang akan dilaksanakan . Diskusi berlangsung dengan menggunakan aplikasi Zoom Meeting.

Tahap berikutmya dalam pesiapan pengabdian masyarakat ini adalah perancangan Materi dan pembuatan poster bergambar gambaran mengenai kasus Neck Paindan cara stretching cervical. Sebelum menyampaikan Poster bergambar Tim Pengabdian Masyarakat menyampaikan materi terkait dengan kasus Neck Painyaitu :Pengertian, etiologi, patofisiologi, cara stretching cervical. Selanjutnya mengirim Poster ini berisi tentang latihan stretching cervical.

Adapun Metode kegiatan diskusi selama pengabdian masyarakat pada siswa SMA 5 Merangin dengan mengirim materi dan poster bergambar yang terkait dengan stretching cervical.

\section{Pelaksanaan}

Pada tahap ini mulai dilakukan sosialisasi dan edukasi terkait stretching cervical dengan poster bergambar melalui online dengan aplikasi Zoom Meeting, materi power point mengenai kasus Neck Paindan poster stretching cervical di jelaskan kepada siswa SMA 5 Merangin, kemudian dilakukan diskusi/ Tanya jawab.

\section{Monitoring dan Evaluasi}

Monitoring dan evaluasi (Monev) dilakukan secara langsung kepada sasaran. Cakupan Monev dalam kegiatan ini meliputi monev perencanaan dan pelaksanaan dan evaluasi hasil.

Monitoring dan evaluasi dilakukan dengan memberikan angket secara online (melalui google form). . Evaluasi ini bertujuan untuk mengetahui sejauh mana respon dan peningkatan pemahaman serta pengetahuan masyarakat terkait Pengabdian Masyarakat yang sudah dilaksanakan. Cakupan monev dalam kegiatan ini meliputi empat aspek, yaitu sebagai berikut .

Cakupan Monev dalam kegiatan ini meliputi monev perencanaan dan pelaksanaan dan evaluasi hasil

Hasil evaluasi baik melalui tanya jawab melalui aplikasi Zoom Meeting tersebut adalah rata-rata siswa mengetahui dan dapat mempraktekkan cara stretching cervical dengan benar, serta keluhan nyeri leher dan kaku kuduk berkurang.

\section{HASIL DAN PEMBAHASAN}

Edukasi atau yang sering juga disebut Pendidikan merupakan segala upaya yang direncanakan untuk mempengaruhi orang lain baik individu, kelompok maupun mayarakat sehingga melakukan apa yang diharapkan oleh pelaku Pendidikan. Dalam kamus besar Bahasa Indonesia (KBBI) Pendidikan berasal dari kata dasar didik (mendidik), yaitu memelihara dan memberi latihan (ajaran pimpinan) mengenai akhlak dan kecerdasan pikiran.

Kegiatan Pengabdian masyarakat ini mengangkat tema "Edukasi stretching cervical pada kasus Neck Pain di SMA 5 Merangin melaluin online dengan aplikasi Zoom Meeting di SMA 5 Merangin pada bulan Februari 2021 yang sasarannya adalah siswa SMA 5 Merangin. Pengabdian masyarakat ini dilakukan oleh 2 orang orang tim dosen dari program studi D-III Fisioterapi dan dibantu oleh Mahasiswa/mahasiswi Program Studi D3 Fisioterapi STIKes Baiturrahim Jambi, dihadiri oleh siswa/siswi SMA 5 Merangin.

Adapun Kegiatan yang telah dilakukan adalah menyampaikan materi power point dan poster bergambar mengenai kasus tanesion headache dan stretching cervical yang bertujuan untuk mengurangi nyeri dan kaku kuduk yang dirasakan siswa/I yang disebabkan 
pembelajaran online selama masa Pandemi Covid-19.

Penanganan nyeri adalah suatu tindakan dengan tujuan mengurangi rasa nyeri, rasa nyeri dapat dikurangi dengan melakukan terapi farmakologis maupun non-farmakologis, penyebab paling umum nyeri leher pada pekerja kantoran adalah postur yang buruk saat beraktivitas dan posisi ergonomi yang kurang baik, posisi statis saat bekerja dan penggunaan gadget dalam waktu yang lama, faktor penyebab tersebut akan menimbulkan permasalahan otot pada regio leher yaitu pemendekan dan spasme maka terapi non-farmakologis yang dapat dilakukan diantaranya adalah streching exercise.

Stretching adalah istilah yang digunakan untuk memanjangkan atau meregangkan struktur jaringan lunak yang memendek, stretching juga berfungsi untuk menimbulkan efek rileks dan mengurangi nyeri dan spasme. (Yilinen, 2006) selain stretching modalitas fisioterapi yang sering digunakan untuk mengatasi rasa nyeri adalah kompres panas, terapi panas superfisial pada permukaan kulit telah digunakan selama beberapa dekade untuk mengurangi nyeri (Heinrichs, 2003). Terapi panas bekerja dengan meningkatkan aliran darah, melebarkan pembuluh darah, meningkatkan oksigen dan pengiriman nutrisi ke jaringan lokal, dan mengurangi kekakuan sendi dengan cara meningkatkan elastisitas otot (Gatlin \& Sculmeister, 2007).

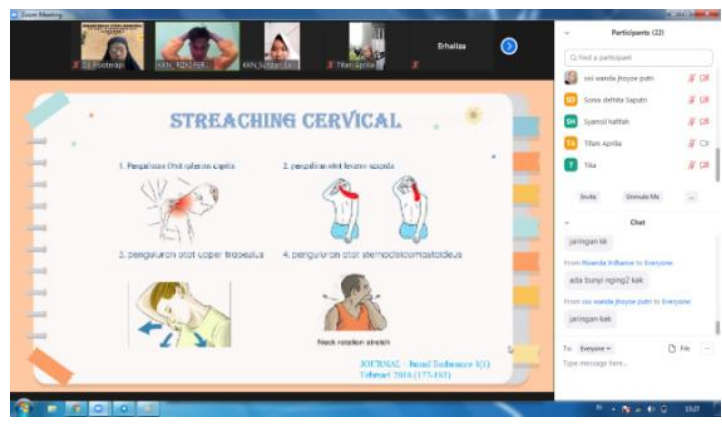

Gambar 1. Penyampaian Materi melalui Zoom Meeting

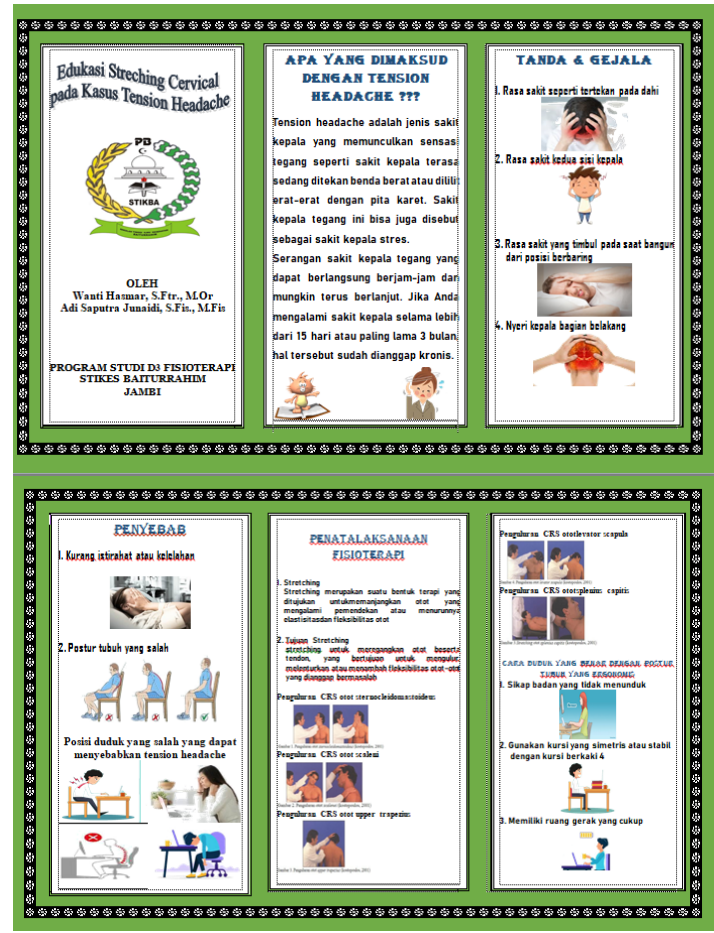

Gambar 4. Leaflet Streching Cervical

\section{KESIMPULAN DAN SARAN}

\section{Kesimpulan}

Setelah tim melaksanakan kegiatan pengabdian masyarakat pada siswa SMA 5 Merangin yang mengikuti melalui Zoom Meeting dapat mempraktekkan dan memahami tentang Neck Paindan cara melakukan stretching cervical.

\section{Saran}

Hendaknya edukasi stretching cervical ini dapat terus dilaksanakan di SMA 5 Merangin agar dapat memberikan pengetahuan pada siswa/i mengenai penanganan nyeri leher dan kaku kuduk selam pembelajaran secara online.

\section{UCAPAN TERIMAKASIH}

Tim Pengabdian mengucapkan terimakasih kepada STIKes Baiturrahim Jambi atas dukungan moril serta materil sehingga kegiatan ini dapat terlaksana dengan baik. 
DAFTAR PUSTAKA

Suryawijaya, E. E. (2017). Korelasi

Tension-Type Headache dengan

Gangguan Kualitas Hidup

Mahasiswa. Neurona Vol. 34.

Artikel Penelitian.

http://www.neurona.web.id/paper/1

005.pdf.

Buckley, J., Bull, P. N. and Poulton, R.

(2015). Tension-Type Headache: A

Life-Course Review. Journal of

Headache \& Pain Management. Vol.

1 No. 1:2.

https://www.academia.edu/23918201/

Tension-Type Headache A Life-

Course_Review.

Falavigna, A dan Teles Robert. (2013),

'Association between primary headaches and depression in young adults in southern Brazil. Revista da Associacao Medica Brasileira. Elsevier, 59(6), pp. 589-593. doi:10.1016/j.ramb.2013.06.014.

Bendtsen, L. (2009). Tension - Type Headache. Neurologic Clinics. 27(3), pp. 525-535.

https://www.sciencedirect.com/scienc e/article/abs/pii/S0733861908001734 ?via\%3Dihub.

doi:10.1016/j.ncl.2008.11.010. 